\title{
CONHECIMENTO SOBRE PREVENÇÃO E TRATAMENTO DE ÚLCERAS DE PRESSÃO ENTRE TRABALHADORES DE ENFERMAGEM EM UM HOSPITAL DE MINAS GERAIS
}

Dulce Aparecida Martins ${ }^{1}$, Fabiana Fernandes Rego Soares ${ }^{2}$

RESUMO: O objetivo deste estudo foi identificar o conhecimento da equipe de enfermagem de um hospital de Minas Gerais acerca do tratamento e medidas de prevenção da Úlceras de Pressão (UP). Participaram 15 Técnicos e Auxiliares em Enfermagem das clínicas médica e cirúrgica. Foram identificadas nas respostas medidas preventivas: mudança de decúbito (100\%); hidratação da pele com óleo (60\%); colchão caixa de ovo (80\%); coxim (40\%); massagem (20\%), dentre outras. Para tratamento foram citadas coberturas, medicamentos e soluções. Quanto à competência dos profissionais 33,3\% disseram seguir prescrição médica e nenhum citou a prescrição do enfermeiro. Os resultados demonstraram que a equipe de enfermagem do hospital possui conhecimento de diversas práticas recomendadas tanto para a prevenção quanto para o tratamento de UP, apesar de citarem condutas errôneas e ultrapassadas. A equipe desconhece o papel do enfermeiro frente ao cuidado de feridas, apontando para a necessidade da realização de educação continuada.

PALAVRAS-CHAVE: Úlcera de pressão; Prevenção; Tratamento; Enfermagem.

\section{KNOWLEDGE ON PREVENTION AND TREATMENT OF PRESSURE ULCERS AMONGST NURSES IN A HOSPITAL IN MINAS GERAIS-BRAZIL}

\begin{abstract}
This study aimed to identify nursing team's knowledge on treatment and preventive measures of pressure ulcers at a hospital in the Minas Gerais State, Brazil. Fifteen nursing technicians and assistants from medical and surgical clinics participated in this study. The following preventive measures were identified in their answers: changes in the patients' lying position (100\%); moisturizing the skin with oil (60\%); eggshell mattress (80\%); cushion (40\%); massage (20\%), among others. As for treatments, coverings, medicines and solutions were quoted. As for the competence of these professionals, 33,3\% stated that they followed medical prescription, and none of them quoted nursing prescription. The results of this study demonstrated that the nursing team in this hospital knows several recommended practices both for prevention and treatment of PU, although some mentioned old fashioned and misled behaviors. The team ignores nurses' role in wound caring, pointing to the need of ongoing education.
\end{abstract}

KEYWORDS: Pressure Ulcer; Prevention; Treatment; Nursing.

\section{CONOCIMIENTO SOBRE PRECAUCIÓN Y TRATAMIENTO DE ÚLCERA DE PRESIÓN, ENTRE TRABAJADORES DE ENFERMERÍA EN UN HOSPITAL DE MINAS GERAIS- BRASIL}

RESUMEN: Este estudio tiene como objetivo identificar el conocimiento del equipo de enfermería del hospital referente a tratamiento y a medidas de prevención de la UP. Los sujetos del estudio fueron 15 profesionales técnicos y ayudantes en enfermería de las clínicas médicas y quirúrgicas. Fue solicitado que contestasen, en la escrita, a una pregunta norteadora. Los discursos fueram agrupados en categorias analizadas bajo la óptica de la literatura especializada. Fueram identificados, en las respuestas, las siguientes medidas preventivas: cambio de decubitus (100\%); hidratación de la piel con el aceite (60\%); colchón “caja de huevos” (80\%); amortiguador (40\%); masaje (20\%), entre otros. Para tratamiento, fueran citadas cubiertas, medicinas y soluciones. Cuanto a la capacidad de los profesionales 33,3\% hablaron que siguen la orientación médica y nadie hablou de la prescrición del enfermero. Los resultados de este estudio demostraron que el equipo de enfermería del hospital tiene conocimiento de diversas prácticas recomendadas tanto para la precaución cuanto para el tratamiento de UP, a pesar de citaren comportamientos erróneos y antiguos. El equipo desconoce la función del enfermero delante al cuidado de heridas, apuntando para la necesidad de realización de educación continua.

PALABRAS CLAVE: Úlcera de presión; Prevención; Tratamiento; Enfermería.

\footnotetext{
${ }^{1}$ Enfermeira. Mestre em Enfermagem Psiquiátrica. Docente do Departamento de Enfermagem. Universidade Federal dos Vales do Jequitinhonha e Mucuri-UFVJM.

${ }^{2}$ Acadêmica do oitavo período de Graduação em Enfermagem. Departamento de Enfermagem . UFVJM.
}

Autor correspondente:

Dulce Aparecida Martins

Rua Jasmins, 131 - 39100-000 - Diamantina-MG

Recebido: 18/09/07

E-mail:dulcediamanti@yahoo.com.br.

Aprovado: 17/03/08 


\section{INTRODUÇÃO}

A Úlcera de Pressão (UP) pode ser definida como "uma área localizada de necrose celular que tende a se desenvolver quando o tecido mole é comprimido entre uma proeminência óssea e uma superfície dura por um período prolongado de tempo"(1). São causadas por fatores intrínsecos e extrínsecos ao paciente. A pressão, o cisalhamento, a fricção e a umidade em um paciente acamado, são fatores extrínsecos que podem levar ao aparecimento destas lesões.

A pressão é considerada o principal fator causador desse tipo de lesão, sendo que o efeito patológico no tecido pode ser atribuído à intensidade da pressão, duração da mesma e tolerância tecidual ${ }^{(2-3)}$.

Dentre os fatores intrínsecos, destacam-se a idade, o estado nutricional, a perfusão tecidual, o uso de alguns medicamentos e as doenças crônicas como o diabetes mellitus e doenças cardiovasculares ${ }^{(1-3)}$.

No Brasil, existem poucos estudos isolados em termos de prevalência e incidência de úlceras de pressão, sendo esses os elementos capazes de demonstrar a amplitude do problema.

A partir do estudo ${ }^{(4)}$, realizado em um Hospital Universitário na cidade de São Paulo, no qual foram avaliados 211 pacientes considerados de risco durante três meses consecutivos, nas unidades médicocirúrgicas, cuidado semi-intensivo e intensivo encontrou-se incidência global de UP de 39,8\%. Desses 211 pacientes internados 84 desenvolveram úlceras de pressão.

Em estudo no Hospital São Paulo(5) ${ }^{(5)} 78$ portadores de úlcera de pressão foi observado que 68\% da amostra desenvolveu UP no hospital, sendo que $43,7 \%$ eram pré-úlceras.

Estatísticas de países da América do Norte e Europa apontam prevalência de UP em portadores de Lesão Medular de $20 \%$ a $60 \%$ e em pacientes de UTI a Incidência é de 0,4 a 38\%; Úlceras de Pressão adquiridas em sala de cirurgia indicou taxas entre 5 a $45 \%{ }^{(1)}$.

A natureza multifatorial da UP requer um esforço de todos os membros de uma equipe multidisciplinar para preveni-las e tratá-las, entretanto, cabe à equipe de enfermagem a maior parcela do cuidado. Estes são responsáveis pelo cuidado direto e pelo gerenciamento da assistência, portanto precisam estar preparados para isso(6).

Não há estudo científico que define, numericamente, a prevalência e a incidência de úlceras de pressão nos pacientes internados neste hospital no interior de Minas Gerais. Porém, observamos nos períodos de estágio neste hospital, que esses índices podem ser elevados.

A observação, nos períodos de estágio curricular, da situação dos pacientes e dos vários casos de UP estágio I, mostrou que não são contempladas medidas preventivas contra o avanço dessas feridas. Isto permitiu supor que há um déficit de conhecimento das intervenções preventivas e de tratamento por pessoal de enfermagem e, ou problemas nas condições de trabalho na instituição.

Além do desconforto e sofrimento causados ao paciente já enfermo, o tratamento das úlceras de pressão constitui um dispêndio financeiro muito maior do que as medidas de prevenção. Estas se constituem principalmente de ações, manejos e materiais de custo consideravelmente menores que os de fins terapêuticos. Assim, é importante que os profissionais da saúde atuem na prevenção das UPs. Um trabalho eficaz de prevenção pressupõe o conhecimento da etiologia e também da realidade da instituição.

O presente estudo teve como objetivo avaliar o conhecimento da equipe de enfermagem de um hospital no interior de Minas Gerais sobre tratamento e medidas de prevenção de úlceras de pressão e identificar as dificuldades dessa equipe, sobre como atuar frente a um paciente susceptível às úlceras de pressão.

\section{MATERIAIS E MÉTODOS}

Buscou-se identificar o conhecimento da equipe de enfermagem de um hospital de médio porte no interior de Minas Gerais, a respeito de formas de prevenção e de tratamento de úlceras de pressão. Os sujeitos do estudo são constituídos pelos Técnicos e Auxiliares de Enfermagem das clínicas médica e cirúrgica do referido hospital, em um total de 15 profissionais. Foi apresentada aos sujeitos uma pergunta norteadora: Descreva o que você realiza, no hospital, para prevenir o surgimento de úlceras de pressão e para tratá-las. Os dados obtidos foram agrupados em categorias e comparados ao preconizado pela literatura científica especializada. Foram atendidos os princípios da Resolução 196/96 acerca da ética na pesquisa com seres humanos.

\section{RESULTADOS E DISCUSSÃO}

Entre os 15 sujeitos que responderam ao 
questionário todos citaram separadamente as medidas realizadas para prevenção e para tratamento das úlceras de pressão.

Como medidas preventivas, os resultados indicaram que $100 \%$ dos sujeitos utilizam a mudança de decúbito como medida preventiva à UP. A mudança de decúbito evita a compressão prolongada e conseqüente redução da irrigação sanguínea local, portanto deve ser feita pelo menos a cada duas horas se não houver contra-indicações relacionadas às condições gerais do paciente ${ }^{(1)}$.

Nove profissionais (60\%) disseram que realizam a hidratação da pele com óleo. A hidratação com óleo da pele do paciente em risco potencial para o surgimento de úlceras de pressão é indicada, por evitar o ressecamento da pele e a conseqüente diminuição da elasticidade, fatores que resultam em fissuras e rompimento das camadas da pele ${ }^{(7)}$.

Em estudo $^{(8)}$ a respeito da utilização do óleo de girassol na prevenção de UP, concluiu-se que o emprego deste óleo é uma opção satisfatória, pois ele é composto de ácidos graxos essenciais, possui propriedades emolientes, apresenta baixo custo e é de fácil acesso.

O uso de colchão caixa de ovo foi citado por 12 entrevistados (80\%). É indicado o uso de um colchão especial que reduz a pressão, como colchão de ar ou colchão d'água. O colchão caixa de ovo aumenta o conforto, porém não reduz a pressão ${ }^{(1)}$.

A utilização de coxim foi relatada por 6 pessoas (40\%). Esta conduta contribui para evitar UP, sendo que travesseiros ou almofadas de espuma devem ser usados para manter as proeminências ósseas longe de contato direto uma com a outra. Os calcanhares devem ser mantidos levantados da cama usando um travesseiro sob a panturrilha ${ }^{(1)}$.

A realização de massagem foi citada por 3 dos sujeitos (20\%). Ressalta-se que a massagem em proeminências ósseas é contra-indicada quando já teve início o processo de formação de UP. Cinco profissionais $(33,3 \%)$ relataram manter o paciente seco/realizar higiene do paciente. Esta é uma medida fundamental tanto para evitar o surgimento de UP quanto para o conforto do paciente e evolução positiva do estado de saúde do mesmo. Quatro sujeitos (26,6\%) relataram manter as roupas de cama bem organizadas/esticadas. A associação desta conduta à movimentação correta do paciente no leito é uma medida de grande valor para evitar a UP, pois evita a fricção e o cisalhamento e conseqüente formação de ferida ${ }^{(1)}$.

Um estudo, em hospital universitário de São
Paulo, os autores ${ }^{(9)}$ identificaram a fricção e o cisalhamento como fatores de risco mais importantes para ocorrência de UP.

Três participantes (20\%) citaram a alimentação como intervenção para prevenção da UP. A alteração da nutrição pode afetar o desenvolvimento da úlcera de pressão, sendo que o organismo subnutrido apresenta alteração no transporte de oxigênio e diminuição da resistência à infecção devido ao efeito no sistema imunológico. As deficiências de vitaminas A, C e E também podem contribuir para o desenvolvimento da úlcera de pressão devido ao papel que estas vitaminas têm na síntese do colágeno,

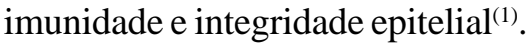

Dois sujeitos (13,3\%) relataram o uso de benjoim como medida de prevenção das UPs. O uso dessa solução como forma preventiva de UP não é indicada ${ }^{(1)}$.

A utilização de filme PVC foi citada por 2 sujeitos (13,3\%). O filme PVC, neste caso, é uma substituição ao filme de poliuretano, devido ao baixo custo do primeiro em comparação ao segundo. A adequação deste tipo de material para a prevenção de UP não foi comprovada por estudos científicos. Esta foi a forma encontrada pelos Técnicos e Auxiliares de enfermagem do hospital, de adequar a necessidade de materiais para a assistência à situação financeira da instituição.

Ainda como medida preventiva para úlceras de pressão, foi citada por um sujeito:

\section{Elevar um pouco a cabeceira, \pm 30 graus.}

A cabeceira da cama de paciente com risco de surgimento de UP deve ser elevada o mínimo possível e por pouco tempo (ângulo máximo de 30 graus) ${ }^{(1)}$.

Para tratamento foram citadas coberturas, medicamentos e soluções. Entre as coberturas, três sujeitos (20\%) citaram a gaze. A gaze possui propriedade de absorver moderadamente líquidos, por capilaridade, remover tecido necrótico superficial (quando usada úmido-seca), preencher espaços mortos e pode ser usada como curativo secundário ${ }^{(10)}$. Existem vários tipos de gazes, a verdadeira é feita com $100 \%$ de algodão. Seu uso é indicado para grandes feridas com grande volume de exsudato para absorção, e apresenta baixo custo. Não deve ser usada para proteção de úlceras no estágio $\mathrm{I}^{(7)}$.

O uso de filme PVC, foi relatado por quatro sujeitos (26,6\%). A adequação deste tipo de material para o tratamento de úlceras de pressão não foi comprovada por estudos científicos. Trata-se de uma 
forma encontrada pelos técnicos e auxiliares de enfermagem do hospital, de adequar a necessidade de materiais para a assistência à situação financeira da instituição.

A utilização de hidrocolóide foi citada por 6 sujeitos (40\%). Este tipo de cobertura é indicado para o tratamento de feridas limpas e na prevenção de UP. É contra-indicada em feridas infectadas e altamente exudativas. A permanência da placa de hidrocolóide está diretamente vinculada ao volume de exudato da ferida ${ }^{(10-11)}$. Podem reduzir a dor da ferida e não requerem o curativo secundário. Possui custo inicial elevado. O uso desta cobertura na região sacral é limitado, pois tende a enrugar-se criando uma pressão $\operatorname{extra}^{(7)}$.

O uso de hidrogel foi citado por um sujeito (6,6\%). Este curativo hidrata a ferida, auxiliando o desbridamento autolítico, é fácil de manusear, não libera partículas no leito da lesão ${ }^{(10-11)}$.

O uso de carvão ativado foi citado por dois sujeitos (13,3\%). Trata-se de uma cobertura composta de tecido de carvão ativado, impregnado com prata, envolto externamente por uma película de nylon, que auxilia na diminuição da carga bacteriana ${ }^{(7)}$.

A referência aos medicamentos e soluções como medidas de tratamento para úlceras de pressão apontou que quatro sujeitos (26,6\%) utilizam a solução fisiológica. O uso dessa solução compreende a melhor técnica de limpeza do leito da ferida através da irrigação com jatos, pois é suficiente para remover corpos estranhos e os tecidos frouxamente aderidos, além de preservar o tecido de granulação neoformado ${ }^{(10)}$.

$\mathrm{O}$ tratamento feito com gaze embebida em solução fisiológica favorece o processo de autólise, a degradação do tecido desvitalizado pela ação de enzimas e ainda estimula a formação do tecido de granulação ${ }^{(11)}$.

Três sujeitos (20\%) relataram o uso de alginato como medida de tratamento para UP. Os alginatos são compostos que apresentam atividade hemostática e aceleram a cicatrização $0^{(10-11)}$.

Quatro pessoas (26,6\%) apontaram a colagenase como medida de tratamento das UPs. Trata-se de uma enzima isolada seletiva para o tecido necrótico que causa danos mínimos em tecidos saudáveis e auxilia o debridamento da lesão ${ }^{(10-11)}$.

Dois entrevistados (13,3\%) citaram o uso de sulfadiazina de prata. Este é um anti-bacteriano tópico freqüentemente prescrito para o tratamento de feridas. Possui característica bactericida e bacteriostática devido aos sais de prata ${ }^{(11)}$. Ainda, como forma de tratamento, alguns sujeitos fizeram outras citações

Manter o mesmo em quarto separado quando possível (S.1).

Esta conduta pode ser uma forma de evitar a contaminação cruzada entre pacientes com diferentes afecções, porém não se trata de uma medida necessariamente recomendável.

Na presença de tecido necrótico um sujeito refere o debridamento. A remoção de tecido necrótico da ferida é de extrema importância. Esta manobra favorece a epitelização e acelera a cicatrização da lesão. Se a úlcera atinge o osso existe grande chance de osteomielite, neste caso a lesão deve ser avaliada por profissional capacitado que fará a prescrição do tratamento adequado.

Quanto à competência dos profissionais médico e enfermeiro, cinco sujeitos (33,3\%) relataram seguir prescrição médica. A prescrição do enfermeiro não foi citada por nenhum sujeito. É da competência do profissional enfermeiro realizar a consulta de enfermagem do paciente portador de lesão ou daquele com risco para desenvolvê-la, prescrever e orientar o tratamento, solicitar exames laboratoriais e de Raios $\mathrm{X}$ quando necessários, realizar o procedimento de curativo (limpeza e cobertura) e o desbridamento quando necessário ${ }^{(12)}$.

O tratamento das diversas lesões deve ser prescrito pelo Enfermeiro, preferencialmente pelo especialista na área. Os Técnicos e Auxiliares de Enfermagem devem realizar o procedimento de curativo: limpeza, cobertura, desbridamento autolítico e químico, prescrito e supervisionado pelo Enfermeiro ${ }^{(12)}$.

Estudos têm mostrado que a úlcera de pressão não é de responsabilidade única da enfermagem, pois a sua ocorrência envolve fatores multicausais. Sendo assim, para a prevenção e o tratamento da úlcera de pressão é necessário uma abordagem multidisciplinar para uma visão sistêmica do problema ${ }^{(13-14)}$.

\section{CONSIDERAÇÕES FINAIS}

Os resultados deste estudo demonstram que a equipe de enfermagem desse hospital possui conhecimento de diversas práticas recomendadas tanto para a prevenção quanto para o tratamento de úlcera de pressão, porém com indícios de condutas errôneas e ultrapassadas.

Algumas manobras importantes para evitar o 
surgimento de UP foram pouco citadas. Houve evidência de que os sujeitos desconhecem o papel do enfermeiro frente ao cuidado de feridas.

Ficou evidenciada a necessidade da realização de uma educação continuada com os Auxiliares e Técnicos de Enfermagem da instituição como estratégia incorporar os novos conhecimentos, tecnologias e alternativas disponíveis para utilização em suas práticas e que seja clarificada a responsabilidade e a atuação de cada profissional frente ao cuidado de feridas.

\section{REFERÊNCIAS}

1 Caliri MH L, Piper B, Cardoso LJ. Recomendações para prevenção de úlceras de pressão em adultos. [acesso em 2006 Out 31]. Disponível em: www.eerp.usp.br/ projetos/ulcera.

2 Costa IG. Incidência de úlcera de pressão e fatores de risco relacionados em pacientes de um centro de terapia intensiva [dissertação]. Ribeirão Preto (SP): Escola de Enfermagem de Ribeirão Preto/USP; 2003.

3 Alexandre SG, Sampaio JD, Menezes ALF; Lobo CC Úlcera de pressão: riscos em uma unidade de terapia intensiva. Estima. 2005 Set;3(3); ed esp.

4 Rogenski NMB, Santos VLCG. Estudo sobre a incidência de úlceras por pressão em um hospital universitário. Rev Latino-am Enferm [periódico na Internet]. $2005 \mathrm{Jul} /$ Ago [acesso em 2005 Jul 15]13(4). Disponível em: www.scielo.br.

5 Blanes L, Duarte IS, Calil JÁ, Ferreira LM. Avaliação clínica e epidemiológica das úlceras por pressão em pacientes internados no Hospital São Paulo. Rev Assoc Méd Brás. 2004 Abr; 50(2). Disponível em: http:// www.scielo.br

6 Rangel EML, Prado KG, Machry AL, Rusticil ACF, Caliri MHL. Prática de graduandos de enfermagem referentes a prevenção e tratamento de úlcera de pressão. Rev Latino-Am Enferm [periódico na Internet]. 1999 Abr [acesso em 2005 Jul 15]7(2). Disponível em: www.scielo.br.

7 Agency for Health Care Policy and Research (AHCPR): Diretrizes para melhoria da qualidade do cuidado. EUA 1998 [acesso em 2006 Out 31] Disponível em: www.eerp.usp.br/projetos/ulcera.

8 Fernandes LM, Braz E. A utilização do óleo de girassol na prevenção de úlceras de pressão em pacientes críticos. Nursing. 2002 Jan;44:29-34.

9 Conejo S, Santos VCG, Rogenski NMB, Baptista CMC, Silva FJ. Úlceras por pressão na alta hospitalar: prevalência e fatores de risco. Estima 2005 Set; 3(3); ed esp.

10 Borges EL, Saar SRC, Magalhães MBB. Feridas: como tratar. Belo Horizonte: Coopmed; 2001.

11 Universidade Estadual de Campinas (SP). Grupo de Estudos de Feridas (GEFE): Manual de tratamento de feridas. Campinas: Hospital das Clínicas; 1999.

12 Brasil. Resolução no . 65/00, de 22 de maio de 2000. Dispõe sobre as competências dos profissionais de enfermagem na prevenção e tratamento das lesões cutâneas, obedecendo à Sistematização da Assistência de Enfermagem (SAE). Conselho Regional de Enfermagem de Minas Gerais - COREN-MG. Belo Horizonte, 22 de maio de 2000.

13 Rabeh SAN. Úlcera de pressão: a clarificação do conceito e estratégias para divulgação do conhecimento na literatura de enfermagem [dissertação]. Ribeirão Preto (SP): Escola de Enfermagem de Ribeirão Preto/USP; 2001.

14 Rangel EML. Conhecimento, práticas e fontes de informação de enfermeiros de um hospital sobre a prevenção e tratamento da úlcera de pressão [dissertação]. Ribeirão Preto (SP): Escola de Enfermagem de Ribeirão Preto; 2004. 